\title{
Evidence for Env-V2 sieve effect in breakthrough SIV MAC251 infections in rhesus monkeys vaccinated with Ad26/MVA and MVA/Ad26 constructs
}

\author{
S Sina², S Tovanabutra², E Sanders-Buell ${ }^{2}$, A Bates², M Bose², S Howell ${ }^{2}$, G Ibitamuno², M Lazzaro², A O'Sullivan², \\ J Lee², T Cervenka², J Kuroiwa², K Baldwin², DH Barouch', M Robb², R O'Connell², NL Michael², JH Kim², \\ $M$ Rolland ${ }^{2^{*}}$
}

From AIDS Vaccine 2012

Boston, MA, USA. 9-12 September 2012

\section{Background}

We had previously shown that rhesus monkeys receiving Ad26/MVA and MVA/Ad26 vaccines expressing SIV $_{\text {SME543 }}$ were protected against SIV $_{\text {MAC251 }}$ challenge (doi:10.1038/nature10766). Protection was associated with Env-specific binding ELISA antibody responses, including V2-specific antibodies.

\section{Methods}

We amplified 66 sequences from the SIV MAC251 $_{\text {chal- }}$ lenge stock, and 409 near-full length genomes from 13 vaccine and 13 control monkeys. A series of pre-specified phylogenetic and statistical tests for sieve effects was performed.

\section{Results}

The mean pairwise AA diversity among the 66 SIVMAC251 Env sequences was $0.38 \%$, and they differed from the vaccine strain SIV SME543 (Env) by $21.94 \%$. The repeated low-dose challenge resulted in infections with an average of 1.7 founder variants - with no evidence that the vaccine restricted the number of variants $(\mathrm{p}=$ $0.813)$. We explored whether the vaccine induced a sieve effect, i.e. whether breakthrough viruses differed between the vaccine and control groups. There was no difference for full-length Env sequences. Focusing on Env segments preferentially recognized by vaccinated monkeys in antibody arrays, we identified a sieve effect in the Env-V2 segment AA163-193: sequences from vaccinated animals were more divergent from the vaccine SIV $_{\text {SME543 }}$ or from the challenge stock SIV $_{\text {MAC251 }}$ than sequences in control animals $(\mathrm{p} \leq 0.002)$.

\section{Conclusion}

The sieve effect in Env-V2, combined with Env-V2-specific binding antibodies identified as a correlate of protection against SIV MAC251 acquisition in the study, provide evidence supporting the importance of protective responses directed against the Env-V2 region.

\section{Author details}

'BIDMC, Harvard Medical School, and Ragon Institute, Boston, MA, USA. ${ }^{2}$ U.S. Military HIV Research Program/Henry M. Jackson Foundation, Bethesda, MD, USA

Published: 13 September 2012

\section{doi:10.1186/1742-4690-9-S2-032}

Cite this article as: Sina et al:: Evidence for Env-V2 sieve effect in breakthrough SIV MAC251 infections in rhesus monkeys vaccinated with Ad26/MVA and MVA/Ad26 constructs. Retrovirology 2012 9(Suppl 2):O32.

\footnotetext{
${ }^{2}$ U.S. Military HIV Research Program/Henry M. Jackson Foundation, Bethesda, MD, USA

Full list of author information is available at the end of the article
}

(c) 2012 Sina et al; licensee BioMed Central Ltd. This is an Open Access article distributed under the terms of the Creative Commons 